\title{
The Agonists of Peroxisome Proliferator-Activated Receptor- $\gamma$ for Liver Fibrosis
}

\author{
Jingjing $\mathrm{Li}^{1,2}$ \\ Chuanyong Guo $\mathbb{D}^{1,2}$ \\ Jianye $\mathrm{Wu}^{\mathrm{I}}$ \\ 'Department of Gastroenterology, Putuo \\ People's Hospital, Tongji University, \\ Shanghai, 200060, People's Republic of \\ China; ${ }^{2}$ Department of Gastroenterology, \\ Shanghai Tenth People's Hospital, Tongji \\ University, Shanghai, 200072, People's \\ Republic of China
}

Correspondence: Jianye Wu

Tel +86-2I-32274550

Email wjymail@163.com

\begin{abstract}
Liver fibrosis is a common link in the transformation of acute and chronic liver diseases to cirrhosis. It is of great clinical significance to study the factors associated with the induction of liver fibrosis and elucidate the method of reversal. Peroxisome proliferatoractivated receptors (PPARs) are a class of nuclear transcription factors that can be activated by peroxisome proliferators. PPARs play an important role in fibrosis of various organs, especially the liver, by regulating downstream targeted pathways, such as TGF- $\beta$, MAPKs, and NF- $\kappa \mathrm{B}$ p65. In recent years, the development and screening of PPAR- $\gamma$ ligands have become a focus of research. The PPAR- $\gamma$ ligands include synthetic hypolipidemic and antidiabetic drugs. In addition, microRNAs, IncRNAs, circRNAs and nano new drugs have attracted research interest. In this paper, the research progress of PPAR- $\gamma$ in the pathogenesis and treatment of liver fibrosis was discussed based on the relevant literature in recent years.
\end{abstract}

Keywords: liver fibrosis, PPAR- $\gamma$, HSCs, agonists

\section{Introduction}

The liver is the main metabolic organ in the body and has a strong regeneration ability. If the liver is stimulated by long-term injury and chronic inflammation, liver fibrosis will develop. In the liver fibrosis in rodent and human livers, the liver can reverse to normal function if the main chronic inflammation or injury trigger is eliminated. This conclusion has been confirmed in many studies. ${ }^{1,2}$ These measures include lifestyle, interference, inhibition of hepatitis virus, and other etiological treatment. At the same time, liver fibrosis is accompanied by the activation and inhibition of a variety of pathways, such as the TGF- $\beta / \mathrm{Smad} 3, \mathrm{NF}-\kappa \mathrm{B}$, PPARs, MAPK, NLRP3, hedgehog, Wnt/ $\beta$-catenin, and Notch signaling. ${ }^{1,3}$ Therefore, an in-depth study of the signal pathway of liver fibrosis can provide ideas for prevention and treatment. ${ }^{4}$

Peroxisome proliferator-activated receptors (PPARs) have a variety of biological effects and are closely related to adipocyte differentiation, glucose and lipid metabolism, carcinogenesis, atherosclerosis, and inflammatory response. ${ }^{5,6}$ PPARs contains three subtypes (PPAR- $\alpha, \operatorname{PPAR}-\beta / \delta$, and PPAR- $\gamma$ ) among them, which PPAR- $\gamma$ has undergone the most in-depth research. ${ }^{7-9}$ Studies have shown that PPAR- $\gamma$ improves hepatic steatosis, reduces inflammation and fibrosis, and significantly increases the response rate of hepatitis virus, which plays an essential role in various acute liver injuries and liver cancer. ${ }^{10-12}$ The pathologic process underlying of PPAR- $\gamma$ is complex that involves the activation of HSCs, ECM deposition and other signaling pathways. In recent years, other research interests including 
intestinal flora and epigenetic modification play an important role in the reversal of liver fibrosis. Therefore, it is of great clinical significance to study drugs and mechanisms targeting PPAR- $\gamma$, which may be a target in the treatment of liver fibrosis.

\section{Structure, Function, and Biological Activity of PPARs}

PPARs belong to the hormone nuclear receptor superfamily and are a class of intranuclear receptors activated by peroxisome proliferators. In 1990, PPARs were successfully cloned in mouse liver by Issemann and colleagues. ${ }^{13}$ To date, three subtypes of PPARs (PPAR- $\alpha$, PPAR- $\beta / \delta$, and PPAR- $\gamma$ ) have been found to be co-expressed in most tissues, but the tissue distribution is quite different. PPAR$\gamma$ is on 3p25 and has nine exons. Four kinds of mRNA isomers are produced by selective splicing (PPAR- $\gamma 1$, PPAR- $\gamma 2$, PPAR- $\gamma 3$, and PPAR- $\gamma 4) .{ }^{14}$ PPAR- $\gamma$ is mainly distributed in adipose tissue, but is also found the colon, immune system, and retina. PPAR- $\gamma$ plays a variety of biological functions, including regulating fat and glucose metabolism, inducing tumor cell differentiation and apoptosis, promoting ovulation and anti-atherosclerotic activity, improving heart failure and ventricular remodeling, and inhibiting inflammatory reactions. ${ }^{15-18}$

\section{PPAR- $\gamma$-Related Ligands and Mechanism of Action}

PPAR- $\gamma$ plays an important role by binding and activating ligands, including natural and synthetic ligands. Natural ligands mainly include arachidonic acid and its metabolites, polyunsaturated fatty acid oxidation metabolites and prostaglandin metabolites. The synthetic ligands mainly include thiazolidinediones (troglitazone, rosiglitazone, and pioglitazone), nonsteroidal anti-inflammatory drugs, and leukotriene D4 receptor antagonists. ${ }^{19}$ The $\mathrm{N}$-terminal domain of PPAR- $\gamma$ contains a protein kinase phosphorylation site that can be activated by mitogens. PPAR- $\gamma$, after being activated by ligands, forms a heterodimer with the retinoic acid receptor (RXR), which then binds with the peroxisome proliferator response element (PPRE) of the target gene promoter to activate target gene transcription of factors that have a variety of biological functions. ${ }^{20,21}$ The current study also demonstrated that a variety of traditional Chinese medicine monomer extracts, which play an important role in PPARs. ${ }^{22}$

\section{Mechanisms Underlying Hepatic Fibrosis and PPAR- $\gamma$}

The pathologic process that characterizes liver fibrosis is complex, involving the activation and inhibition of many signaling pathways, from resting hepatic stellate cells (HSC) activation, extracellular matrix (ECM) deposition, and oxidative stress, to lipid metabolism and immune responses. In recent years, there are other research interests, including the role of intestinal flora, the establishment of anaerobic pro-inflammatory microenvironment in tissues, and epigenetic modification in the progress of fibrosis. ${ }^{1,23}$ Intervention in any of these processes, many of which involve PPAR- $\gamma$, will play a positive role in the reversal of liver fibrosis.

\section{Activation of HSCs}

Hepatic fibrosis is the repair response of the liver to various chronic injury stimuli. The main feature of hepatic fibrosis is the continuous generation of ECM exceeding degradation, and the deposition of ECM in the liver develops into irreversible lesions. HSCs are the main source of the ECM and the central link in the occurrence and development of liver fibrosis. ${ }^{24}$ Under normal conditions, HSCs account for $5 \%-15 \%$ of all the hepatic cells in the liver and are in a resting state. HSCs are responsible for the metabolism and storage of vitamin A and fat, and the synthesis and secretion of collagen, glycoproteins, MMPs, and TIMPs. When stimulated by a viral infection, excessive alcohol intake, toxic substances, or other detrimental factors, morphologic changes occur and HSCs will transform into myofibroblasts, which express the main components of $\alpha$-SMA and the ECM, and promote the formation of liver fibrosis. ${ }^{25}$ Recent studies have shown that PPAR- $\gamma$ and GATA6 are necessary for inactivation of human HSCs and regression of liver fibrosis in mice. ${ }^{26,27}$ PPAR- $\gamma$ inhibits HSC activation, proliferation, and increases ECM production. ${ }^{28,29}$ Wang and colleagues reported that PPAR- $\gamma$ is also expressed in normal HSCs, while PPAR- $\gamma$ expression gradually decreases with increased HSC activation stimulated by inflammation or injury, indicating that PPAR- $\gamma$ inhibits HSC activation and maintains its quiescence. ${ }^{30}$ Yavrom upregulated PPAR- $\gamma$ expression by transfecting HSCs with PPAR- $\gamma$ adenovirus vector, which confirmed that the translocation reduced the activation of HSCs; the decrease of type I collagen in veins was the most significant finding. ${ }^{31} \mathrm{Yu}$ and colleagues confirmed that PPAR $-\gamma$ is expressed in primary resting 
HSCs, but is absent in cultured activated HSCs. In contrast, the ectopic expression of PPAR- $\gamma$ in activated HSCs reversed the phenotype of resting cells. ${ }^{32}$ Therefore, PPAR- $\gamma$ involvement in attenuating HSC activation is an important target whether or not liver fibrosis can be reversed. In addition, Zhang et al [reference \#?] believed that platelet-derived growth factor (PDGF) receptor- $\gamma$ inhibits angiogenesis signal transduction through transexpression of PDGF- $\beta$ receptor, resulting in decreased motility of HSCs and decreased expression of vascular endothelial growth factor, thus inhibiting angiogenesis induced by HSCs. Therefore, PPAR- $\gamma$ can also be used as a molecular target for the prevention of hepatic fibrosis and vascular remodeling. ${ }^{33}$

\section{Inflammation and Oxidative Stress}

Oxidative stress and inflammation play an important role in the pathogenesis of the initiation and progression of many liver diseases. ${ }^{34,35}$ ROS promotes the expression of IL- 6 and IL- $1 \beta$ by stimulating intracellular signal cascades, such as NF- $\mathrm{BB}$. In contrast, inflammatory cells, such as monocytes and lymphocytes, also produce additional ROS after activation. ${ }^{36,37}$ PPAR $-\gamma$ is a regulator of cell proliferation and immune responses, and can regulate the expression of related genes and participate in the inflammatory response. It has also been confirmed that PPAR- $\gamma$ plays a strong role in inhibiting liver fibrosis by cross-talk with inflammatory-related factors, such as NF$\kappa \mathrm{B}$ and $\mathrm{AP}-1$, inhibiting $\mathrm{T}$ cell activation and macrophage proliferation and secretion. $4,28,38,39$

\section{Lipid Metabolism}

The liver is an important site for fat metabolism, and plays an important role in fat digestion, absorption, synthesis, and transportation. Liver lipid peroxidation plays a key role in the pathological process of liver fibrosis. Free fatty acids induce high expression of CYP2E1 (the main component of the cytochrome P450 system) and enhance lipid peroxidation in fatty liver. These processes involve chemotactic neutrophils, induction of autoimmune responses, and direct activation hepatic macrophages and HSCs. ${ }^{1,25}$ Fatty cirrhosis has a common histologic feature. That is, the cause of steatosis of liver cells is repeated attacks of the same cause. The first attack causes steatosis of liver cells, thus causing fatty liver. The second attack causes lipid peroxidation, leading to steatohepatitis and liver fibrosis. PPAR- $\gamma$ is highly expressed in adipocytes and is a major regulator of adipogenesis. ${ }^{14}$ PPAR $-\gamma$ can activate the expression of phosphoenolpyruvate carboxykinase and glycerol kinase via transcription, which then participate in the production of triglycerides through different pathways. PPAR- $\gamma$ regulates the glucose content under the action of lipoprotein lipase, then affects the final synthesis of triglycerides by affecting 3-phosphoglycerate. Studies have confirmed that rosiglitazone can reduce liver lipid accumulation and peroxidation in patients with liver fibrosis, which facilitates the reversal of NASH. ${ }^{26}$ The PPAR- $\alpha / \gamma$ agonist, saroglitazar, improves insulin resistance and steatohepatitis in a diet-induced NAFLD animal model. ${ }^{40}$ Indeed, GDF10 blocks PPAR- $\gamma$ activation in the liver and protects the liver from dietinduced liver injury. ${ }^{41}$ These results suggest that PPAR- $\gamma$ plays an effective role in anti-fibrosis by participating in lipid metabolism.

\section{Immune Response}

The regulatory function of immune cells plays an important role in the formation of liver fibrosis, including nonspecific and specific immune cells. The non-specific immune cells mainly include macrophages, natural killer (NK) cells, dendritic cells, and other non-specific cells. Among the cell types, macrophages play an important role in the two-way regulation of liver fibrosis, while NK cells have a wide range of pathogen and activated cell clearance functions. $^{42,43}$ The specific immune cells are mainly $\mathrm{T}$ cells, which play an important role in the occurrence of anti-infective immunity, anti-tumor immunity, and autoimmune diseases. T cells cooperate with IL-17 to inhibit liver inflammation, but whether $\mathrm{T}$ cells can block the formation and mechanism underlying liver fibrosis remains to be studied. ${ }^{44,45}$ Studies have confirmed that PPAR- $\gamma$ participates in the innate immune response, promotes the differentiation and maturation of dendritic cells, and inhibits the uptake of antigen by dendritic cells. Concurrently, dendritic cells migrate to the draining lymph nodes to have an impact on antigen presentation. In addition, it can also have an impact on inflammatory factors and on the regulation of $\mathrm{T}$ cell balance and anti- $\mathrm{T}$ cell proliferation. ${ }^{46,47}$

\section{PPAR- $\gamma$ Targets Anti-Fibrosis Drugs}

PPAR- $\gamma$ signaling pathway has become a new hotspot in drug development; different types of agonists have different effects on liver. ${ }^{48}$ In addition to the natural and synthetic ligands that have been confirmed, many effective components of Chinese herbal medicines can be used as 
PPAR- $\gamma$ agonists to affect liver fibrosis. At the same time, with the development of gene technology, microRNAs, lncRNAs, and nano new drugs have attracted research interest. $^{49}$

\section{Natural Ligands}

Natural ligands of PPAR- $\gamma$ include arachidonic acid and its metabolites, oxidative metabolites of polyunsaturated fatty acids, and prostaglandin metabolites. 15-Deoxy- $\Delta$ 12,14-prostaglandin J 2 (15d-PGJ2) is the most widely studied cyclopentenone prostaglandin, and is also the earliest identified endogenous ligand for PPAR- $\gamma^{50}$ Studies have confirmed that $15 \mathrm{~d}-\mathrm{PGJ} 2$ inhibits TGF- $\beta$ induced expression of CTGF by inhibiting the phosphorylation of Smad2, which may have a favorable preventive effect on liver fibrosis induced by environmental toxicants. ${ }^{51}$ Docosahexaenoic acid (DHA) and eicosatetraenoic acid (EPA) are trace bioactive substances and essential high unsaturated fatty acids in human, animals, and fish. He and his colleagues confirmed that long-term DHA and EPA supplementation inhibits the activation of HSCs via the TGF- $\beta$ and ERK pathways in a PPAR- $\gamma$ dependent manner to alleviate liver fibrosis. ${ }^{52-54}$ Leptin (LP) is a protein hormone secreted by adipose tissue. After entering the blood circulation, LP participates in the regulation of glucose, fat, and energy metabolism and inhibits the synthesis of adipocytes. In 2014, Zhou et al demonstrated that LP induced an increase in GATA2 and inhibited PPAR- $\gamma$ expression, thus increasing the number of activated HSCs in vivo, which provides strong evidence that LP promotes liver fibrosis. ${ }^{55}$ Wai et al subsequently established a GRX cell culture model with PPAR- $\gamma$ gene overexpression, and confirmed that GATA-2 mediated LP expression and promoted the proliferation of HSCs through its binding site with the PPAR- $\gamma$ promoter. ${ }^{56}$ In addition, LP downregulates PPAR- $\gamma$ gene expression in primary cultured rat HSCs by activating the PI-3K/Akt and ERK signaling pathways, which provides new insight into the mechanism underlying LP promotion of liver fibrosis. ${ }^{57}$ Galanin and vitamin $\mathrm{C}$, endogenous factors that negatively regulate the biological effects of LP bioenergy metabolism, inhibit the proliferation of HSCs and the expression of $\alpha$ SMA by increasing PPAR- $\gamma$, which may be of potential significance for elucidating the detailed mechanisms underlying liver fibrosis in diseases with elevated circulating LP levels, such as non-alcoholic fatty hepatitis in obese patients. ${ }^{54,58,59}$

\section{Synthetic Ligands}

PPAR- $\gamma$ synthetic ligands mainly include thiazolidinediones (troglitazone, rosiglitazone, and pioglitazone), nonsteroidal anti-inflammatory drugs, and leukotriene D4 receptor antagonists. In 2005, Marra demonstrated that troglitazone treatment reduces bile duct hyperplasia and fibrosis in a chronic cholestasis model. ${ }^{60}$ At the same time, pioglitazone is thought to effectively reduce the levels of PDGF and TIMP-2 expression in a nonalcoholic fatty liver disease model, which helped to inhibit liver fibrosis. ${ }^{39}$ Rosiglitazone, a highly effective PPAR- $\gamma$ agonist, not only delays liver fibrosis induced by Schistosoma japonicum infection and bile duct ligation through downregulation of fibrosis-related genes, including TGF- $\beta 1, \alpha$-SMA, and CoI- $\alpha 1$, but also inhibits the activation of HSCs through miR-124-3p. ${ }^{61-63}$ At the same time, when combined with erythromycin and all-trans retinoic acid in the treatment of liver fibrosis, rosiglitazone has a significant effect. $^{64,65}$ In addition, saroglitazar and ale stimulate PPAR- $\alpha / \gamma$ at the same time, which reduces liver fibrosis by inhibiting TGF- $\beta 1$, PDGF, and neovascularization. ${ }^{64,65}$ In addition to thiazolidinediones, new chemicals have been shown to activate PPAR- $\gamma$. GW570 has an antiinflammatory effect on Kupffer cells in vivo during CCl4 injury, thus inhibiting astrocyte activation and inhibiting fibrosis after injury in a dose-dependent manner. ${ }^{66}$ SC-236, a selective cyclooxygenase- 2 inhibitor, alleviates liver fibrosis via non-parenchymal cell apoptosis and PPAR- $\gamma$ activation. $^{67}$

\section{Traditional Chinese Medicine Extract}

With advances in technology, it has been shown that some traditional Chinese medicine ingredients also lead to PPAR- $\gamma$ ligand activation; curcumin is the most studied drug. In 2003 and 2004, Xu and Zheng found that curcumin significantly induces PPAR- $\gamma$ gene expression in activated HSCs. Blocking the trans-activation activity with PPAR- $\gamma$ antagonists significantly eliminates the inhibitory effect of curcumin on cell proliferation. It has been shown that curcumin has antioxidant potential and has no adverse effects on health, which makes curcumin a potential antifibrosis syndrome for the prevention and treatment of liver fibrosis. ${ }^{68,69}$ Subsequently, many scholars have carried out a thorough exploration of the mechanism underlying curcumin function. Zhang believes that curcumin activates PPAR- $\gamma$ to inhibit the angiogenesis of hematopoietic stem cells, thereby reducing sinusoidal angiogenesis in liver 
fibrosis, while Qi has proved that PPAR- $\gamma$ is a key factor in inhibiting HSC activation and DLK1 expression by blocking the Shh signal pathway. ${ }^{70,71}$ Zhai proposed that coactivator- $1 \alpha$ of PPAR- $\gamma$ is key to the role of curcumin. Curcumin promotes the expression of SOD- $1 \alpha$ via the AMPK pathway, which leads to an increase in SOD-2 transcription and activity. ${ }^{72}$ These results may provide a new explanation for curcumin inhibition of HSC activation and hepatic fibrosis.

Other active Chinese medicines can play an antifibrosis role as a target of PPAR- $\gamma$. Polyphenol, rosmarinus acid (RA), and baicalin (BC) are important components of liver protection. The research shows that RA and $\mathrm{BC}$ significantly improve the histopathologic changes following $\mathrm{CCl} 4$ injury and BDL-induced liver fibrosis models. The underlying mechanism is to reduce the TGF- $\beta 1$ and Wnt pathways and inhibit HSC activation. ${ }^{73,74}$ Puerarin inhibits collagen deposition and plays an anti-fibrosis role by blocking the PI3K/Akt pathway. ${ }^{75}$ Activation of PPAR- $\gamma$ by tetra-methylpyrazine leads to the reverse expression of HIF-1 $\alpha$ through a Smrt-dependent mechanism, which improves liver injury, angiogenesis, and vascular remodeling in rats with CCL4-induced liver fibrosis, and is thus of therapeutic significance for the peripheral cell biology and hepatic fibrosis of HSCs. ${ }^{76}$ Resveratrol reduces the accumulation of lipid droplets in cells and PPAR- $\gamma$ regulates the activation of HSCs and hepatic fibrosis by epigenetic regulation. ${ }^{77}$ Hydroxysafflor yellow A inhibits carbon tetrachloride-induced liver fibrosis by regulating the PPAR- $\gamma /$ P38 MAPK signaling pathway, while the antagonist, GW9662, significantly reduces the above effect. ${ }^{78}$ Crocin treatment significantly reduces the serum liver enzyme level and improves liver CYP2E1 mRNA levels and the pathologic changes of liver tissue. ${ }^{38}$ The alcohol extract of Rhus verniciflua fruit can prevent liver fibrosis induced by carbon tetrachloride in mice by inhibiting inflammatory factors [83]. Lycopene inhibits HSC activation, and regulates cell lipid storage and signal transduction. ${ }^{79}$ In addition, picroside I, Achyranthes bidentata polysaccharide, rhubarb fruit extract, capsaicin, diosgenin, and umbelliferone participate in the regulation of PPAR- $\gamma$ in liver fibrosis. $^{38,80-85}$

\section{MicroRNAs}

Gene therapy is another major thrust of research, especially microRNAs, which have been used in the diagnosis and treatment of various diseases. Winkler and his colleagues [86] identified a miRNA network composed of 8
miRNA hubs and 54 target genes, and found that let-7, miR-30, miR-29c, miR-335, and miR-338 downregulate the key structure, signal, and remodeling components of the ECM. In addition, miR-130a and miR-130b were found to decrease PPAR- $\gamma$ mRNA expression by targeting the expression of the 3 'untranslated region of PPAR- $\gamma$, a process that may be mediated by TGF- $\beta 1 .{ }^{86}$ In activated artificial blood stem cells, the expression of PPAR- $\gamma$ was negatively correlated with the expression of miR-34a and miR-34c, indicating that the miR-34 family may participate in the process of liver fibrosis by targeting PPAR $-\gamma .{ }^{87}$ MiR-27b regulates the expression of PPAR mRNA in LX2 cells and lays a foundation for further study of liver fibrosis. ${ }^{88}$ MiR-29a increases PPAR- $\gamma$ expression and negatively regulates HSC activation by inhibiting BRD4 and $\mathrm{EZH} 2$ functions, thus making it a promising target for drug therapy of liver fibrosis. ${ }^{89}$ In human liver fibrosis, miR-942 inhibits PPAR- $\gamma$, then promotes the activation of HSCs induced by TGF- $\beta 1$; an effect that is blocked by the inhibition of miR-942. ${ }^{90}$ Therefore, if we can effectively regulate the related microRNAs, we can effectively improve liver fibrosis.

\section{Other Ligands}

In addition, there are some ligands which can play an effective role. For example, AT1 receptor blockers and the PPAR- $\gamma$ activator, telmisartan, can reduce experimental liver fibrosis induced by Schistosoma mansoni infection. ${ }^{91}$ Diosmin alleviates radiation-induced liver fibrosis by promoting PPAR $-\gamma$ expression and inhibiting the typical Wnt signaling pathway activated by miR-17-5p. ${ }^{92}$ Polymer nanoparticles co-administered with Hedgehog inhibitors and PPAR- $\gamma$ agonists may be used to treat liver fibrosis by interfering with complex liver fibrosis cascade reactions. ${ }^{93}$ The role of ligands in liver fibrosis is summarized in Table 1 and Figure 1.

\section{Conclusions and Perspectives}

PPAR- $\gamma$ participates in the process of liver fibrosis by inhibiting HSCs activation and proliferation and increasing ECM production by regulating TGF- $\beta$ and other pathways to achieve an anti-fibrosis effect. ${ }^{94}$ According to the current research, PPAR- $\gamma$ is closely related to liver fibrosis, so there is an incentive to study PPAR- $\gamma$ ligands. In addition to the related ligands described in this review, many ligands, such as lncRNAs and circRNAs, are still under study. At present, it has only been preliminarily proved that they can act as endogenous competitive RNA through 
Table I Summary of PPAR- $\gamma$ Ligands in Liver Fibrosis

\begin{tabular}{|c|c|c|c|c|c|}
\hline Type & Agonists & Key Factor & Models & Dosage & Ref. \\
\hline \multirow[t]{7}{*}{ Natural } & $15 \mathrm{~d}-\mathrm{PG} \mid 2$ & TGF- $\beta$ & Нер3B, HepG2, Huh-7 & $5-10 \mu \mathrm{M}, 24 \mathrm{~h}$ & [5। $]$ \\
\hline & \multirow[t]{2}{*}{ DHA } & \multirow[t]{2}{*}{ TGF- $\beta$} & HSC-LX2 & $0.05 \% \mathrm{v} / \mathrm{v}, 24 \mathrm{~h}$ & \multirow[t]{2}{*}{ [53] } \\
\hline & & & ICR mice & $20 \mathrm{mg} / \mathrm{kg} / \mathrm{d}, 4 \mathrm{w}$ & \\
\hline & Galanin & TGF- $\beta$ & Primary HSCs, HSC-T6 & $\mathrm{I}-10000 \mathrm{nM}, 24 \mathrm{~h}$ & [54] \\
\hline & \multirow[t]{2}{*}{ Leptin } & \multirow[t]{2}{*}{ GATA-2 } & HSCs & $100 \mathrm{ng} / \mathrm{mL}, 12 \mathrm{~h}$ & \multirow[t]{2}{*}[55,56]{} \\
\hline & & & C57BL mice & I $\mu g / g, 4 w$ & \\
\hline & Vitamin C & TGF- $\beta$ & SMP30 KO mice & $1.5 \mathrm{~g} / \mathrm{L}, 16 \mathrm{w}$ & [59] \\
\hline \multirow[t]{8}{*}{ Synthetic } & Pioglitazone & PDGF & C57BL mice & $3 \mathrm{mg} / \mathrm{kg} / \mathrm{d}, 4 \mathrm{w}$ & [39] \\
\hline & Thiazolidinedione & $\alpha$-SMA & SD Rats & $0.2 \% \mathrm{w} / \mathrm{w}, 4 \mathrm{w}$ & [60] \\
\hline & \multirow[t]{2}{*}{ Rosiglitazone } & TGF- $\beta$ & Kunming mice & $4 \mathrm{mg} / \mathrm{kg} / \mathrm{d}, 6 \mathrm{w}$ & \multirow[t]{2}{*}[61,62]{} \\
\hline & & $N F-\kappa B$ & HepPPAR- $\gamma$ KO mice & $30 \mathrm{mg} / \mathrm{kg} / \mathrm{d}, 2 \mathrm{w}$ & \\
\hline & Saroglitazar & TGF- $\beta$ & SD Rats & $3 \mathrm{mg} / \mathrm{kg} / \mathrm{d}, 4 \mathrm{w}$ & [64] \\
\hline & Aleglitazar & TNF- $\alpha$ & SD Rats & $0.3 \mathrm{mg} / \mathrm{kg} / \mathrm{d}, 3 \mathrm{w}$ & [65] \\
\hline & GW570 & TNF- $\alpha$ & SD Rats & $10 \mathrm{mg} / \mathrm{kg} / \mathrm{d}, 2 \mathrm{w}$ & [66] \\
\hline & SC-236 & Apoptosis & SD Rats & $6 \mathrm{mg} / \mathrm{kg} / \mathrm{d}, 4 \mathrm{w}$ & [67] \\
\hline \multirow[t]{14}{*}{ Traditional } & Crocin & TNF- $\alpha$ & SD Rats & $20-80 \mathrm{mg} / \mathrm{kg} / \mathrm{d}, 4 \mathrm{w}$ & [38] \\
\hline & \multirow[t]{2}{*}{ Curcumin } & \multirow[t]{2}{*}{ SOD2 } & Primary HSCs & I5-20 $\mu \mathrm{M}, 24 \mathrm{~h}$ & \multirow[t]{2}{*}[71,72]{} \\
\hline & & & SD Rats & $400 \mathrm{mg} / \mathrm{kg} / \mathrm{d}, 4 \mathrm{w}$ & \\
\hline & \multirow[t]{2}{*}{ Baicalin } & \multirow[t]{2}{*}{ TGF- $\beta$} & SD Rats & $25-100 \mathrm{mg} / \mathrm{kg} / \mathrm{d}, 8 \mathrm{w}$ & \multirow[t]{2}{*}[73,74]{} \\
\hline & & & Primary HSCs, & $67.5-270 \mu \mathrm{M}, 24 \mathrm{~h}$ & \\
\hline & Puerarin & $\mathrm{PI} 3 \mathrm{~K} / \mathrm{Akt}$ & SD Rats & $200-800 \mathrm{mg} / \mathrm{kg} / \mathrm{d}, 8 \mathrm{w}$ & [75] \\
\hline & \multirow[t]{2}{*}{ Ligustrazine } & & HSC-T6 & $10-30 \mu \mathrm{M}, 24 \mathrm{~h}$ & \multirow[t]{2}{*}{ [76] } \\
\hline & & & SD Rats & $50-200 \mathrm{mg} / \mathrm{kg} / \mathrm{d}, 4 \mathrm{w}$ & \\
\hline & Resveratrol & IRTI & HSC-GRX & $0.1 \mu \mathrm{M}, 24 \mathrm{~h}$ & [77] \\
\hline & Hydroxysafflor yellow A & P38 MAPK & SD Rats & $10 \mathrm{mg} / \mathrm{mL}, 8 \mathrm{w}$ & [78] \\
\hline & Lycopene & Lipid metabolism & HSC-GRX & $\mathrm{I}-5 \mu \mathrm{mol} / \mathrm{L}, 24 \mathrm{~h}$ & [79] \\
\hline & Picroside & TGF- $\beta$ & C57BL mice & $25-50 \mathrm{mg} / \mathrm{kg} / \mathrm{d}, 8 \mathrm{w}$ & [80] \\
\hline & Ethanol extract & TNF- $\alpha$ & Kunming mice & $400-800 \mathrm{mg} / \mathrm{kg} / \mathrm{d}, 6 \mathrm{w}$ & [82] \\
\hline & Umbelliferone & TGF- $\beta$ & SD Rats & $25-100 \mathrm{mg} / \mathrm{kg} / \mathrm{d}, 8 \mathrm{w}$ & [83] \\
\hline \multirow[t]{5}{*}{ MiR-RNAs } & miR-I30 & TGF- $\beta$ & Primary HSCs, HSC-T6 & $0.1-100 \mathrm{pmol} / \mathrm{L}, 48 \mathrm{~h}$ & [86] \\
\hline & miR-34 & TGF- $\beta$ & Primary HSCs, LX2 & $10-50 \mathrm{nmol} / \mathrm{L}, 48 \mathrm{~h}$ & [87] \\
\hline & $\mathrm{miR}-27 \mathrm{~b}$ & TGF- $\beta$ & $\mathrm{LX} 2$ & $50-100 \mathrm{nmol} / \mathrm{L}, 48 \mathrm{~h}$ & [88] \\
\hline & $\operatorname{miR}-29 a$ & BRD4 & Primary HSCs & $25 \mathrm{nmol} / \mathrm{L}, 24 \mathrm{~h}$ & [89] \\
\hline & miR-942 & $\alpha$-SMA & hHSCs, LX2 & $100 \mathrm{nmol} / \mathrm{L}, 24 \mathrm{~h}$ & {$[90]$} \\
\hline
\end{tabular}




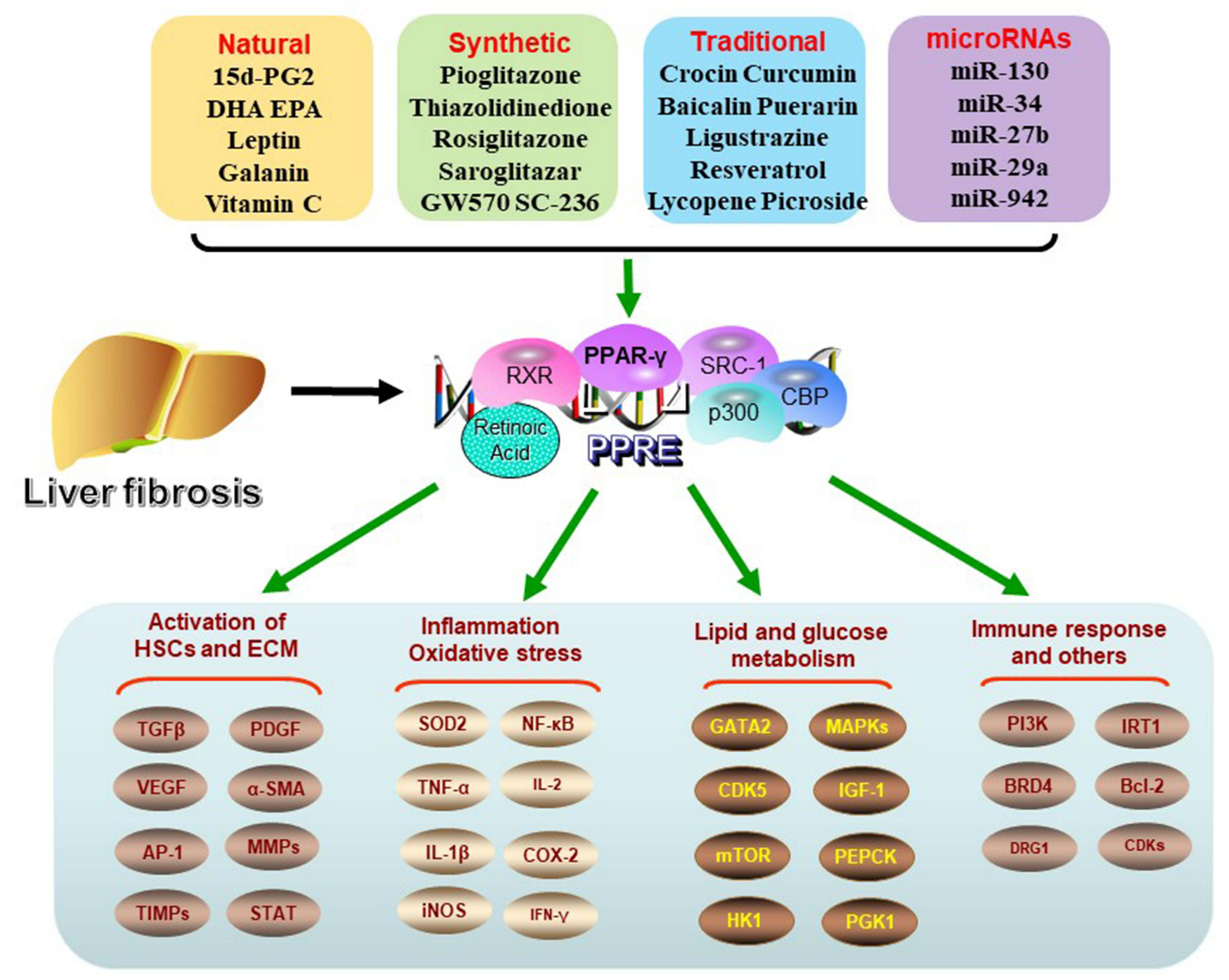

Figure I Regulation of PPAR- $\gamma$ ligands and signal pathways. In liver fibrosis, PPAR- $\gamma$ activation is inhibited. After activation by related ligands, PPAR- $\gamma$ forms heterodimer with retinoic acid receptor (RXR), then plays a variety of biological roles by binding peroxisome proliferator response element (PPRE) to activate target gene transcription. Its biological processes involve the activation of HSCs, the deposition of ECM, oxidative and inflammatory reactions, glucose and lipid metabolism and immune response related pathways.

microRNAs, but the research on direct regulation is rare. We expect more effective ligands to be developed and applied in clinical treatment. The elucidation of the mutual regulation between PPAR- $\gamma$ ligands and signal pathways, and the initiation of targeted gene therapy technology at the gene level will open a new way for the prevention and treatment of liver fibrosis and lay a foundation for the development of new anti-liver fibrosis drugs.

\section{Acknowledgments}

This work was supported by China Foundation for Hepatitis Prevention and Control WBN liver Disease Research Fund (grant No. CFHPC2019031), and the Shanghai Sailing Program (grant No. 20YF1443300).

\section{Disclosure}

The authors report no conflicts of interest in this work.

\section{References}

1. Kisseleva T, Brenner D. Molecular and cellular mechanisms of liver fibrosis and its regression. Nat Rev Gastroenterol Hepatol. 2020.

2. Trivedi P, Wang S, Friedman SL. The Power of Plasticity-Metabolic Regulation of Hepatic Stellate Cells. Cell Metab. 2020.

3. Ioannou GN. HCC surveillance after SVR in patients with F3/F4 fibrosis. J Hepatol. 2021;74(2):458-465.

4. Arroyo V, Angeli P, Moreau R, et al. The systemic inflammation hypothesis: towards a new paradigm of acute decompensation and multiorgan failure in cirrhosis. J Hepatol. 2020.

5. Han X, Wu Y, Yang Q, Cao G. Peroxisome proliferator-activated receptors in the pathogenesis and therapies of liver fibrosis. Pharmacol Ther. 2020;222:107791. 
6. Wu L, Li J, Feng J, et al. Crosstalk between PPARs and gut microbiota in NAFLD. Biomed Pharmacother. 2021;136:111255.

7. Cordoba-Chacon J. Loss of Hepatocyte-Specific PPARgamma Expression Ameliorates Early Events of Steatohepatitis in Mice Fed the Methionine and Choline-Deficient Diet. PPAR Res. 2020;2020:9735083.

8. Zardi E, Navarini L, Sambataro G, et al. Hepatic PPARs: their role in liver physiology, fibrosis and treatment. Curr Med Chem. 2013;20 (27):3370-3396.

9. Staels B, Rubenstrunk A, Noel B, et al. Hepatoprotective effects of the dual peroxisome proliferator-activated receptor alpha/delta agonist, GFT505, in rodent models of nonalcoholic fatty liver disease/nonalcoholic steatohepatitis. Hepatology. 2013;58 (6):1941-1952.

10. Mo W, Wang C, Li J, et al. Fucosterol Protects against Concanavalin A-Induced Acute Liver Injury: focus on P38 MAPK/NF-kappaB Pathway Activity. Gastroenterol Res Pract. 2018;2018:2824139.

11. Wu L, Guo C, Wu J. Therapeutic potential of PPARgamma natural agonists in liver diseases. $J$ Cell Mol Med. 2020;24(5):2736-2748.

12. Xiang S, Chen K, Xu L, Wang T, Guo C. Bergenin Exerts Hepatoprotective Effects by Inhibiting the Release of Inflammatory Factors, Apoptosis and Autophagy via the PPAR-gamma Pathway. Drug Des Devel Ther. 2020;14:129-143.

13. Issemann I, Green S. Activation of a member of the steroid hormone receptor superfamily by peroxisome proliferators. Nature. 1990;347 (6294):645-650.

14. Wagner N, Wagner KD. The Role of PPARs in Disease. Cells. 2020;9:11.

15. Christofides A, Konstantinidou E, Jani C, Boussiotis V. The role of peroxisome proliferator-activated receptors (PPAR) in immune responses. Metabolism. 2020;154338.

16. Wagner N, Wagner K. PPARs and Angiogenesis-Implications in Pathology. Int J Mol Sci. 2020;21:16.

17. Liu Y, Wang J, Luo S, Zhan Y, Lu Q. The roles of PPAR $\gamma$ and its agonists in autoimmune diseases: a comprehensive review. J Autoimmun. 2020;113:102510.

18. Trumper V, Wittig I, Heidler J, Richter F, Brune B, von Knethen A. Redox Regulation of PPARgamma in Polarized Macrophages. PPAR Res. 2020;2020:8253831.

19. Yemchenko YO, Shynkevych VI, Ishcheikin KY, Kaidashev IP. PPAR-Gamma Agonist Pioglitazone Reduced CD68+ but Not CD163+ Macrophage Dermal Infiltration in Obese Psoriatic Patients. PPAR Res. 2020;2020:4548012.

20. Yu S, Xu H. Couple dynamics: pPAR $\gamma$ and its ligand partners. Structure. 2012;20(1):2-4.

21. Kytikova OY, Perelman JM, Novgorodtseva TP, et al. Peroxisome Proliferator-Activated Receptors as a Therapeutic Target in Asthma. PPAR Res. 2020;2020:8906968.

22. Stasilowicz A, Tomala A, Podolak I, Cielecka-Piontek J. Cannabis sativa L. as a Natural Drug Meeting the Criteria of a Multitarget Approach to Treatment. Int J Mol Sci. 2021;22:2.

23. Zhao Q, Fan Y, Zhao J, Gao S, Zhao Z, Wang K. DNA methylation patterns of peroxisome proliferator-activated receptor gamma gene associated with liver fibrosis and inflammation in chronic hepatitis B. J Viral Hepat. 2013;20(6):430-437.

24. Mahdinloo S, Kiaie S, Amiri A, Hemmati S, Valizadeh H, ZakeriMilani P. Efficient drug and gene delivery to liver fibrosis: rationale, recent advances, and perspectives. Acta pharmaceutica Sinica B. 2020;10(7):1279-1293.

25. Berumen J, Baglieri J, Kisseleva T, Mekeel K. Liver fibrosis: pathophysiology and clinical implications. Wiley Interdiscip Rev Syst Biol Med. 2020;e1499.

26. Ni XX, Li XY, Wang Q, Hua J. Regulation of peroxisome proliferator-activated receptor-gamma activity affects the hepatic stellate cell activation and the progression of NASH via TGF-beta1/ Smad signaling pathway. J Physiol Biochem. 2020.
27. Liu X, Xu J, Rosenthal S, et al. Identification of Lineage-Specific Transcription Factors That Prevent Activation of Hepatic Stellate Cells and Promote Fibrosis Resolution. Gastroenterology. 2020;158 (6): 1728-1744.

28. Quintero P, Arrese M. Nuclear control of inflammation and fibrosis in nonalcoholic steatohepatitis: therapeutic potential of dual peroxisome proliferator-activated receptor alpha/delta agonism. Hepatology. 2013;58(6):1881-1884.

29. Wang Y, Nakajima T, Gonzalez FJ, Tanaka N. PPARs as Metabolic Regulators in the Liver: lessons from Liver-Specific PPAR-Null Mice. Int J Mol Sci. 2020;21:6.

30. Wang Z, Xu JP, Zheng YC, et al. Peroxisome proliferator-activated receptor gamma inhibits hepatic fibrosis in rats. Hepatobiliary Pancreat Dis Int. 2011;10(1):64-71.

31. Yavrom S, Chen L, Xiong S, Wang J, Rippe RA, Tsukamoto H. Peroxisome proliferator-activated receptor gamma suppresses proximal alpha1(I) collagen promoter via inhibition of p300-facilitated NF-I binding to DNA in hepatic stellate cells. J Biol Chem. 2005;280(49):40650-40659.

32. Yu J, Zhang S, Chu ES, et al. Peroxisome proliferator-activated receptors gamma reverses hepatic nutritional fibrosis in mice and suppresses activation of hepatic stellate cells in vitro. Int $J$ Biochem Cell Biol. 2010;42(6):948-957.

33. Zhang F, Kong D, Chen L, et al. Peroxisome proliferator-activated receptor- $\gamma$ interrupts angiogenic signal transduction by transrepression of platelet-derived growth factor- $\beta$ receptor in hepatic stellate cells. J Cell Sci. 2014;127:305-314.

34. Chiabotto G, Pasquino C, Camussi G, Bruno S. Molecular Pathways Modulated by Mesenchymal Stromal Cells and Their Extracellular Vesicles in Experimental Models of Liver Fibrosis. Front Cell Dev Biol. 2020;8:594794.

35. Samuel D. Systemic inflammation and liver cirrhosis complications: driving or secondary event? How to square the circle? J Hepatol. 2021.

36. Ramos-Tovar E, Muriel P. Molecular Mechanisms That Link Oxidative Stress, Inflammation, and Fibrosis in the Liver. Antioxidants. 2020;9:12.

37. Dallio M, Sangineto M, Romeo M, et al. Immunity as Cornerstone of Non-Alcoholic Fatty Liver Disease: the Contribution of Oxidative Stress in the Disease Progression. Int J Mol Sci. 2021;22(1):564.

38. Chhimwal J, Sharma S, Kulurkar P, Patial V. Crocin attenuates CCl4-induced liver fibrosis via PPAR-gamma mediated modulation of inflammation and fibrogenesis in rats. Hum Exp Toxicol. 2020;39 (12):1639-1649.

39. Deng W, Meng Z, Sun A, Yang Z. Pioglitazone suppresses inflammation and fibrosis in nonalcoholic fatty liver disease by down-regulating PDGF and TIMP-2: evidence from in vitro study. Cancer Biomarkers. 2017;20(4):411-415.

40. Kumar DP, Caffrey R, Marioneaux J, et al. The PPAR alpha/gamma Agonist Saroglitazar Improves Insulin Resistance and Steatohepatitis in a Diet Induced Animal Model of Nonalcoholic Fatty Liver Disease. Sci Rep. 2020;10(1):9330.

41. Platko K, Lebeau PF, Byun JH, et al. GDF10 blocks hepatic PPARgamma activation to protect against diet-induced liver injury. Mol Metab. 2019;27:62-74.

42. Gan J, Zheng SJ, Mao XR, Li JF. Invariant natural killer T cells: not to be ignored in liver disease. J Dig Dis. 2021.

43. Sepulveda-Crespo D, Resino S, Martinez I. Strategies Targeting the Innate Immune Response for the Treatment of Hepatitis C Virus-Associated Liver Fibrosis. Drugs. 2021.

44. Rha MS, Han JW, Koh JY, et al. Impaired antibacterial response of liver sinusoidal Vgamma9(+)Vdelta2(+) $\mathrm{T}$ cells in patients with chronic liver disease. Gut. 2021.

45. Liang Q, Hu Y, Zhang M, et al. The T Cell Receptor Immune Repertoire Protects the Liver From Reconsitution. Front Immunol. 2020;11:584979. 
46. Christofides A, Konstantinidou E, Jani C, Boussiotis VA. The role of peroxisome proliferator-activated receptors (PPAR) in immune responses. Metabolism. 2021;114:154338.

47. Silveira LS, Batatinha HAP, Castoldi A, et al. Exercise rescues the immune response fine-tuned impaired by peroxisome proliferator-activated receptors gamma deletion in macrophages. J Cell Physiol. 2019;234(4):5241-5251.

48. Lefere S, Puengel T, Hundertmark J, et al. Differential effects of selective- and pan-PPAR agonists on experimental steatohepatitis and hepatic macrophages(). J Hepatol. 2020;73(4):757-770.

49. Zhang F, Lu Y, Zheng S. Peroxisome proliferator-activated receptor- $\gamma$ cross-regulation of signaling events implicated in liver fibrogenesis. Cell Signal. 2012;24(3):596-605.

50. Li J, Guo C, Wu J. 15-Deoxy-(12,14)-Prostaglandin J2 (15d-PGJ2), an Endogenous Ligand of PPAR-gamma: function and Mechanism. PPAR Res. 2019;2019:7242030.

51. Suk FM, Chen CH, Lin SY, et al. 15-deoxy-Delta(12,14)prostaglandin $\mathrm{J}(2)$ inhibits fibrogenic response in human hepatoma cells. Toxicol Lett. 2009;187(1):22-27.

52. He J, Bai K, Hong B, Zhang F, Zheng S. Docosahexaenoic acid attenuates carbon tetrachloride-induced hepatic fibrosis in rats. Int Immunopharmacol. 2017;53:56-62.

53. He J, Hong B, Bian M, et al. Docosahexaenoic acid inhibits hepatic stellate cell activation to attenuate liver fibrosis in a PPAR $\gamma$ dependent manner. Int Immunopharmacol. 2019;75:105816.

54. He L, Li Z, Zhou D, et al. Galanin receptor 2 mediates antifibrogenic effects of galanin on hepatic stellate cells. Exp Ther Med. 2016;12 (5):3375-3380.

55. Zhou Q, Guan W, Qiao H, et al. GATA binding protein 2 mediates leptin inhibition of PPAR $\gamma 1$ expression in hepatic stellate cells and contributes to hepatic stellate cell activation. Biochim Biophys Acta. 2014;1842:2367-2377.

56. Wai K, Liang Y, Zhou L, et al. The protective effects of Acanthus ilicifolius alkaloid $\mathrm{A}$ and its derivatives on pro- and anti-inflammatory cytokines in rats with hepatic fibrosis. Biotechnol Appl Biochem. 2015;62(4):537-546.

57. Zhou Y, Jia X, Wang G, Wang X, Liu J. PI-3 K/AKT and ERK signaling pathways mediate leptin-induced inhibition of PPARgamma gene expression in primary rat hepatic stellate cells. Mol Cell Biochem. 2009;325(1-2):131-139.

58. Guan $\mathrm{W}$, Cheng $\mathrm{F}, \mathrm{Wu} \mathrm{H}$, et al. GATA binding protein 3 is correlated with leptin regulation of PPAR $\gamma 1$ in hepatic stellate cells. J Cell Mol Med. 2017;21(3):568-578.

59. Park JK, Ki MR, Lee HR, et al. Vitamin C deficiency attenuates liver fibrosis by way of up-regulated peroxisome proliferator-activated receptor-gamma expression in senescence marker protein 30 knockout mice. Hepatology. 2010;51(5):1766-1777.

60. Marra F, DeFranco R, Robino G, et al. Thiazolidinedione treatment inhibits bile duct proliferation and fibrosis in a rat model of chronic cholestasis. World J Gastroenterol. 2005;11(32):4931-4938.

61. Chen H, He YW, Liu WQ, Zhang JH. Rosiglitazone prevents murine hepatic fibrosis induced by Schistosoma japonicum. World $J$ Gastroenterol. 2008;14(18):2905-2911.

62. Wei Z, Zhao D, Zhang Y, et al. Rosiglitazone ameliorates bile duct ligation-induced liver fibrosis by down-regulating NF-kappaB-TNFalpha signaling pathway in a PPARgamma-dependent manner. Biochem Biophys Res Commun. 2019;519(4):854-860.

63. Zhi S, Chen S, Li Y, Li J, Zheng Y, Yu F. Rosiglitazone Inhibits Activation of Hepatic Stellate Cells via Up-Regulating Micro-RNA124-3p to Alleviate Hepatic Fibrosis. Dig Dis Sci. 2019;64 (6):1560-1570.

64. Makled M, Sharawy M, El-Awady M. The dual PPAR- $\alpha / \gamma$ agonist saroglitazar ameliorates thioacetamide-induced liver fibrosis in rats through regulating leptin. Naunyn-Schmiedeberg's arch pharmacol. 2019;392(12):1569-1576.
65. Tsai H, Li T, Huang C, et al. Beneficial Effects of the Peroxisome Proliferator-Activated Receptor $\alpha / \gamma$ Agonist Aleglitazar on Progressive Hepatic and Splanchnic Abnormalities in Cirrhotic Rats with Portal Hypertension. Am J Pathol. 2018;188 (7):1608-1624.

66. Yang L, Stimpson SA, Chen L, Wallace Harrington W, Rockey DC. Effectiveness of the PPARgamma agonist, GW570, in liver fibrosis. Inflamm Res. 2010;59(12):1061-1071.

67. Planagumà $\mathrm{A}$, Clària $\mathrm{J}$, Miquel $\mathrm{R}$, et al. The selective cyclooxygenase-2 inhibitor SC-236 reduces liver fibrosis by mechanisms involving non-parenchymal cell apoptosis and PPARgamma activation. FASEB j. 2005;19(9):1120-1122.

68. $\mathrm{Xu} \mathrm{J}, \mathrm{Fu} \mathrm{Y,} \mathrm{Chen} \mathrm{A.} \mathrm{Activation} \mathrm{of} \mathrm{peroxisome} \mathrm{proliferator-activated}$ receptor-gamma contributes to the inhibitory effects of curcumin on rat hepatic stellate cell growth. Am J Physiol Gastrointest Liver Physiol. 2003;285(1):G20-30.

69. Zheng S, Chen A. Activation of PPARgamma is required for curcumin to induce apoptosis and to inhibit the expression of extracellular matrix genes in hepatic stellate cells in vitro. Biochem J. 2004;384:149-157.

70. Zhang F, Zhang Z, Chen L, et al. Curcumin attenuates angiogenesis in liver fibrosis and inhibits angiogenic properties of hepatic stellate cells. J Cell Mol Med. 2014;18(7):1392-1406.

71. Qiu J, Zhou Q, Zhai X, Jia X, Zhou Y. Curcumin regulates delta-like homolog 1 expression in activated hepatic stellate cell. Eur J Pharmacol. 2014;728:9-15.

72. Zhai X, Qiao H, Guan W, et al. Curcumin regulates peroxisome proliferator-activated receptor- $\gamma$ coactivator- $1 \alpha$ expression by AMPK pathway in hepatic stellate cells in vitro. Eur J Pharmacol. 2015;746:56-62.

73. Qiao H, Han H, Hong D, Ren Z, Chen Y, Zhou C. Protective effects of baicalin on carbon tetrachloride induced liver injury by activating PPARgamma and inhibiting TGFbeta1. Pharm Biol. 2011;49 (1):38-45.

74. Yang M, Chiang Y, Higashiyama R, et al. Rosmarinic acid and baicalin epigenetically derepress peroxisomal proliferator-activated receptor $\gamma$ in hepatic stellate cells for their antifibrotic effect. Hepatology. 2012;55(4):1271-1281.

75. Guo C, Xu L, He Q, Liang T, Duan X, Li R. Anti-fibrotic effects of puerarin on $\mathrm{CCl} 4$-induced hepatic fibrosis in rats possibly through the regulation of PPAR- $\gamma$ expression and inhibition of PI3K/Akt pathway. Food Chem Toxicol. 2013;56:436-442.

76. Zhang F, Lu S, He J, et al. Ligand Activation of PPAR $\gamma$ by Ligustrazine Suppresses Pericyte Functions of Hepatic Stellate Cells via SMRT-Mediated Transrepression of HIF-1 $\alpha$. Theranostics. 2018;8(3):610-626.

77. de Souza I, Martins L, de Vasconcelos M, et al. Resveratrol Regulates the Quiescence-Like Induction of Activated Stellate Cells by Modulating the PPAR $\gamma /$ SIRT1 Ratio. J Cell Biochem. 2015;116 (10):2304-2312.

78. Liu Q, Wang C, Liu Z, et al. Hydroxysafflor yellow A suppresses liver fibrosis induced by carbon tetrachloride with high-fat diet by regulating PPAR- $\gamma /$ p38 MAPK signaling. Pharm Biol. 2014;52 (9):1085-1093.

79. Elias MB, Oliveira FL, Guma FCR, Martucci RB, Borojevic R, Teodoro AJ. Lycopene inhibits hepatic stellate cell activation and modulates cellular lipid storage and signaling. Food Funct. 2019;10 (4):1974-1984.

80. Xiong K, Shi M, Zhang T, Han H. Protective effect of picroside I against hepatic fibrosis in mice via sphingolipid metabolism, bile acid biosynthesis, and PPAR signaling pathway. Biomed Pharmacother. 2020;131:110683.

81. Zheng M, Li Y, Wang G, et al. Protective effect of cultured bear bile powder against dimethylnitrosamine-induced hepatic fibrosis in rats. Biomed Pharmacother. 2019;112:108701. 
82. Zhou J, Liu X, Chen T, Cheng G, Cai S. Preventive effect of ethanol extract from Chinese sumac fruits against tetrachloromethane-induced liver fibrosis in mice. Food Funct. 2020;11(8):7061-7072.

83. Mahmoud A, Hozayen W, Hasan I, Shaban E, Bin-Jumah M. Umbelliferone Ameliorates CCl-Induced Liver Fibrosis in Rats by Upregulating PPAR $\gamma$ and Attenuating Oxidative Stress, Inflammation, and TGF- $\beta 1 / \mathrm{Smad} 3$ Signaling. Inflammation. 2019;42 (3):1103-1116.

84. Cheng Y, Mai J, Wang M, Chen G, Ping J. Antifibrotic effect of total flavonoids of Astmgali Radix on dimethylnitrosamine-induced liver cirrhosis in rats. Chin J Integr Med. 2017;23(1):48-54.

85. Li J, Dai W, Xia Y, et al. Astaxanthin Inhibits Proliferation and Induces Apoptosis of Human Hepatocellular Carcinoma Cells via Inhibition of Nf-Kappab P65 and Wnt/Beta-Catenin in Vitro. Mar Drugs. 2015;13(10):6064-6081.

86. Li J, Wang F, Xia Y, et al. Astaxanthin Pretreatment Attenuates Hepatic Ischemia Reperfusion-Induced Apoptosis and Autophagy via the ROS/MAPK Pathway in Mice. Mar Drugs. 2015;13 (6):3368-3387.

87. Li X, Chen Y, Wu S, et al. microRNA-34a and microRNA-34c promote the activation of human hepatic stellate cells by targeting peroxisome proliferator-activated receptor $\gamma$. Mol Med Rep. 2015;11 (2):1017-1024.
88. Zhu D, Lyu L, Shen P, et al. rSjP40 protein promotes PPAR $\gamma$ expression in LX-2 cells through microRNA-27b. FASEB j. 2018;32 (9):4798-4803.

89. Huang Y, Kuo H, Yang Y, Wang F. MicroRNA-29a is a key regulon that regulates BRD4 and mitigates liver fibrosis in mice by inhibiting hepatic stellate cell activation. Int J Med Sci. 2019;16(2):212-220.

90. Tao L, Wu L, Zhang W, et al. Peroxisome proliferator-activated receptor $\gamma$ inhibits hepatic stellate cell activation regulated by miR942 in chronic hepatitis B liver fibrosis. Life Sci. 2020;253:117572.

91. Attia Y, Elalkamy E, Hammam O, Mahmoud S, El-Khatib A. Telmisartan, an AT1 receptor blocker and a PPAR gamma activator, alleviates liver fibrosis induced experimentally by Schistosoma mansoni infection. Parasit Vectors. 2013;6:199.

92. Hasan H, Abdel-Rafei M, Galal S. Diosmin attenuates radiationinduced hepatic fibrosis by boosting PPAR- $\gamma$ expression and hampering miR-17-5p-activated canonical Wnt- $\beta$-catenin signaling. Biochemistry Cell Biol. 2017;95(3):400-414.

93. Kumar V, Mundra V, Mahato R. Nanomedicines of Hedgehog inhibitor and PPAR- $\gamma$ agonist for treating liver fibrosis. Pharm Res. 2014;31(5):1158-1169.

94. Zhang F, Kong D, Lu Y, Zheng S. Peroxisome proliferator-activated receptor-gamma as a therapeutic target for hepatic fibrosis: from bench to bedside. Cell Mol Life Sci. 2013;70(2):259-276.

\section{Publish your work in this journal}

Drug Design, Development and Therapy is an international, peerreviewed open-access journal that spans the spectrum of drug design and development through to clinical applications. Clinical outcomes, patient safety, and programs for the development and effective, safe, and sustained use of medicines are a feature of the journal, which has also been accepted for indexing on PubMed Central. The manuscript management system is completely online and includes a very quick and fair peer-review system, which is all easy to use. Visit http://www. dovepress.com/testimonials.php to read real quotes from published authors. 